\title{
Industrial Productivity Convergence in China ${ }^{1}$
}

\author{
Xuemei Bai \\ Department of Statistics, Dongbei University of Finance and Economics, \\ Dalian, 116025, P. R. China \\ Gang $\mathbf{L i}{ }^{*}$ \\ School of Management, University of Surrey, \\ Guildford, GU2 7XH, United Kingdom
}

\begin{abstract}
This paper examines the convergence process of industrial productivity between Chinese regions. Both $\sigma$ - and $\beta$ - convergences are investigated using a panel data set of 30 provinces and autonomous regions over the period 1985-1999. Unconditional $\sigma$ - and $\beta$ convergence methods fail to detect productivity convergence over the whole sample period, although they suggest convergence during a sub-period 1985-1990. The estimates of a human capital enhanced production function, with the constant return to scale constraint, show that productivity gaps between Chinese regions declined during 19851999 with a rate of convergence of around $1.3 \%$ per annum. Similar results are also found when the data are disaggregated into three broader geographic regions.
\end{abstract}

Keywords: convergence; productivity; China; Industry

\footnotetext{
${ }^{1}$ The article should be cited as: Bai X, Li G. (2004). Regional Productivity Convergence in China. Journal of Chinese Economic and Business Studies, 2 (2), pp. 155-168. DOI: 10.1080/14765280410001684805

"Corresponding author: Tel.: +44 1483 686356; fax: +44 1483 686346. Email address: G.Li@ surrey.ac.uk
} 


\section{Introduction}

Regional productivity performance has important implications for government policy making at both national and regional levels in China. The reduction of income inequality and improvement of social welfare in poor areas depend on improvements in production efficiency and labour productivity. Researchers, politicians and policymakers are therefore very interested in finding out whether there is any productivity gap between the richer and poorer regions of China. If significant differences in regional productivity are identified, a key question would be: can poorer regions with lower productivity catch up with their richer counterparts through the process of economic growth? A good understanding of the extent to which regional productivity differs and the causes of this differential is crucial for the formulation of government regional policies.

In recent years, although considerable efforts have been made by researchers in testing income convergence across the Chinese regions during the reform period, the results of the empirical studies have contradictions.. For example, Raiser (1998) and Choi and Li (2000) find some evidence of income convergence, while Fujita and Hu (2001), Gustafsson and Shi (2001) and Yao (1999) suggest that the economic reforms have widened regional disparity (income divergence). These conflicting results are mainly caused by the use of different research methodologies and variations in the sample data used. In a survey of empirical studies on income convergence in China, Wu (2000a) concludes that there is strong evidence to support income convergence during the 1980s, but that the convergence hypothesis is largely rejected during the 1960s-1970s and the 1990s. Other related studies concerning income convergence include Jian, Sachs and Waner (1996), Chen and Feng (2000), Lee (2000), Song, et al (2000), Xu and Zou (2000) and Ravallion and Jalan (1996).

In addition to income convergence, productivity convergence is also studied in order to examine economic growth. The results of income convergence studies are used as references for the analysis of the productivity convergence. However, as Caree, et al, (2000, p. 337) argued, "the mechanisms behind catch-up and convergence of GDP per capita (income) can never be established unless the developments of its lower level of aggregation equivalent of labour productivity are well understood." Therefore, it is of great importance to study productivity convergence, especially on a lower aggregated level. Compared with studies on income convergence, publications on productivity convergence have been sparse. The exception is Gundlach (1997) who examines regional productivity convergence per worker based on the neoclassical growth model. The empirical evidence of the study shows that output productivity converges during the period 1979-1989, and that the rate of convergence is 2.2 per cent. However, this rate of convergence declines over time. Using the stochastic frontier approach, Wu (2000b) finds strong evidence of productivity convergence between the Chinese regions during 1982-1995. However, the measures of productivity defined in $\mathrm{Wu}$ (2000b) are technical efficiency and technical progress, which differ from traditional measures for labour productivity. Both of these papers use aggregated data over all sectors, and no data after the mid1990s have been included.

This present study sets out to examine the output productivity performance between Chinese regions, based on convergence concepts developed in the economic growth literature. In particular, both $\sigma$-convergence and $\beta$-convergence are examined. This study differs from the existing literature on productivity convergence in China in four ways. Firstly, this paper focuses on industrial productivity only, rather than that at a fully aggregated level. Secondly, a human capital enhanced production function is applied for conditional productivity analysis, 
in comparison with unconditional convergence analysis. Thirdly, different measures of physical capital and human capital are defined, and they are superior to the commonly used measures in the literature. Lastly, the data cover the period up to 1999, with the most recent economic development taken into account.

The rest of this paper is organised as follows. Section 2 reviews convergence regressions used in empirical studies. Section 3 proposes an adjusted conditional $\beta$-convergence model for testing regional productivity convergence. This convergence model is developed based on a human capital enhanced Cob-Douglas production function and has a constant return to scale property. Section 4 describes the data used in testing for productivity convergence in China and presents the empirical results. The final section presents the conclusions of the paper.

\section{Review of Convergence Models}

According to Barro and Sala-I-Martin (1992), two types of convergence, $\sigma$ - and $\beta$ convergences, are relevant. The former detects whether regional productivity disparity declines over time, while the latter measures the extent to which the poor regions can catch up with the richer regions in productivity. Although both of these two measures have been used in assessing regional income and/or productivity convergence, the results are not always conclusive. The empirical evidence shows that $\beta$-convergence is a necessary but not a sufficient condition for $\sigma$-convergence (Barro and Sala-I-Martin, 1995 and Caree et al, 2000).

\section{1. $\sigma$-convergence}

The first and most popular method used in testing for $\sigma$-convergence is to examine the time path of standard deviations of productivity across all regions. A declining trend implies $\sigma$ convergence, otherwise no convergence in productivity between the regions under consideration exists.

\section{2. $\beta$-convergence}

$\beta$-convergence can be tested based on the following regression:

$$
p_{i t}=(1-\beta) \mu_{i}+\beta p_{i t-1}+\varepsilon_{i t}
$$

where $p_{i t}$ is a measure of labour productivity in logarithm in region $i$, and $\mu_{i}$ is a constant for region $i$.

Equation (1) is known as the 'Barro-Baumol convergence model' (de la Fuente, 1997; Bliss, 1999), and can be estimated using pooled regression. If the estimated $\beta$ in the model is less than unity, the regional productivities are said to converge toward a steady state in the long run. This is because the effect of each shock and the productivity gap between the rich and poor regions diminish over time. On the other hand, if $\beta$ is greater than unity the shock magnifies itself over time and regional productivities in the rich regions grow faster than those in the poor regions. Therefore the aim of the $\beta$-convergence test is to examine the value of $\beta$ in Equation (1).

When the panel data are used to test for $\beta$-convergence, it is common to transform Equation (1) into Equation (2) by incorporating the individual effects into the disturbance term in Equation (1): 


$$
\Delta p_{i t}=\alpha+(\beta-1) p_{i t-1}+\omega_{i t}
$$

where $\Delta p_{i t}=p_{i t}-p_{i t-1}$ and $\omega_{i t}=\varepsilon_{i t}+(1-\beta) \mu_{i}-\alpha$.

Equation (2) is a typical random effect model, i.e. the model has a common intercept plus a cross-sectional specific effect, $(1-\beta) \mu_{i}-\alpha$. The productivity $\beta$-convergence suggests that the value of $(\beta-1)$ should be less than 0 . If $(\beta-1)$ is greater than 0 , divergence in productivity occurs.

However, Breitung and Meyer (1994) and Goddard and Wilson (2001) show that the random effect model of Equation (2) tends to yield an inconsistent estimate of $\beta$, as the true data generating process (DGP) includes heterogeneous individual effects. A more suitable approach according to these authors is to estimate the following fixed-effect model:

$$
\Delta p_{i t}=(\beta-1)\left(p_{i t-1}-p_{i 0}\right)+\xi_{i t}
$$

where $\xi_{i t}=\varepsilon_{i t}+(1-\beta) \mu_{i}+(\beta-1) p_{i 0}$.

Equation (3) is a fixed-effect specification in which only the heterogeneous regional specific effect $(1-\beta) \mu_{i}+(\beta-1) p_{i 0}$ is included.

Equations (1), (2) and (3) are called unconditional $\beta$-convergence, as there is no explanatory variable involved in the models apart from the lagged productivity itself. Studies that test for income/productivity convergence using these equations have provided little support for the hypothesis of convergence (de la Fuente, 1997). The results of convergence using these models are very sensitive to the choice of initial income/productivity levels as well as to the selection of regions in the sample. For example, Baumol (1986) uses a data set relating to 16 industrialised countries over the period 1870-1970 and finds clear evidence of income convergence. However, when De Long (1988) adds another 6 countries (Ireland, Spain, Portugal, Chile, Argentina and New Zealand) into Baumol's sample, the convergence property disappears completely. This suggests that the use of these models in testing for income/productivity convergence is likely to yield spurious and unreliable results. To improve the performance of $\beta$-convergence regressions, additional variables need to be introduced to replace $\mu_{i}$ in the unconditional convergence equations. These variables aim to capture the observed variations of income/productivity growth disparities between regions that have different economic conditions. The selection of influencing factors in the $\beta$-convergence equation is guided by the theoretical framework. Neo-classical growth theory suggests that a region's income/productivity growth rate tends to be inversely related to its starting level, due to diminishing returns of reproducible capital (Solow, 1956). Endogenous growth theory, on the other hand, would suggest that income/productivity growth is related to the diffusion of technology through knowledge spillover, which in turn leads to the closing of productivity gaps between regions.

In the next section we develop a convergence regression based on an enhanced Cob-Douglas production function to test for productivity convergence between Chinese regions.

\section{A Conditional Productivity Convergence Model for China}


The productivity convergence model used in this paper is derived from the Cob-Douglas production function augmented by a human capital stock variable as an input factor:

$$
Y_{i t}=A_{i}(t) K_{i t}^{a} L_{i t}^{b} H_{i t}^{c}
$$

where $Y_{i t}, K_{i t}, L_{i t}$ and $H_{i t}$ are output, capital, labour and human capital in region $i$ at time $t$, respectively; $a, b$ and $c$ are scale elasticities; $A_{i}$ is the level of technology in region $i$ at time $t$.

Based on Equation (4) labour productivity is expressed as

$$
Y_{i t} / L=A_{i}(t)\left(K_{i t} / L_{i t}\right)^{a} L_{i t}{ }^{a+b+c-1}\left(H_{i t} / L_{i t}\right)^{c}
$$

Assuming a constant return to scale, that is $a+b+c=1$, Equation (5) becomes

$$
Y_{i t} / L=A_{i}(t)\left(K_{i t} / L_{i t}\right)^{a}\left(H_{i t} / L_{i t}\right)^{c}
$$

$K_{i t} / L_{i t}$ and $H_{i t} / L_{i t}$ in Equation (6) are variables that measure the level of capital deepening process and average human capital per employee respectively, both of which should have a positive contribution to productivity growth. The reason why a constant return to scale is assumed in the productivity function (6) is that this avoids the possibility of any multicolinearity problem in Equation (5). It is evident that the regions that have high levels of capital stock are also likely to have high levels of labour force. Hence the capital stock variable tends to be correlated with the labour force variable.

Converting the original data to logarithms on both sides of Equation (6), and then differencing the resulting equation with respect to time, gives:

$$
\Delta p_{i t}=\pi_{i}+a \Delta(k-l)_{i t}+c \Delta(h-l)_{i t}
$$

where $p_{i t}=\ln \left(Y_{i t} / L_{i t}\right),(k-l)_{i t}=\ln \left(K_{i t} / L_{i t}\right)$, and $(h-l)_{i t}=\ln \left(H_{i t} / L_{i t}\right)$.

Following Bairam and McRae (1999), $\pi_{i}$, the rate of technical progress, in this study is defined as:

$$
\pi_{i}=\gamma+\beta\left(Y_{i 0} / L_{i 0}\right)
$$

Hence Equation (7) becomes

$$
\Delta p_{i t}=\gamma+\beta P_{i 0}+a \Delta(k-l)_{i t}+c \Delta(h-l)_{i t}
$$

The convergence hypothesis assumes that productivity growth across regions is inversely related to their initial productivity levels, i.e. the estimated $\beta$ coefficient should be less than 0 .

The inclusion of human capital as an input factor in the production function is important for examining the source of productivity growth in China. Gerschenkron (1952) and Kuznets (1973) suggest that much of the productivity catch-up process may be explained by the diffusion of technological knowledge from the leading economies to the more backward ones, and this is the so-called 'advantages of backwardness'. Competition between regional economies, in the absence of economic and institutional barriers, would lead to fast dissemination of superior productive technologies from the richer economies to the poorer ones. The less productive economies have a lower production basis and they can learn more from the leaders than the leaders can lean from them. Therefore the economies with lower 
productivity will grow faster than their richer counterparts. However, being poor does not necessarily mean that a poor economy will automatically catch up. Accumulation of fixed capital, an educated and well-trained labour force and R\&D are all important contributing factors for the catch-up process (Wolff, 2000).

The new growth theory advocated by Mankiw et al (1992), Lucas (1993) and Romer (1990) suggests that the level of human capital affects the growth of productivity through knowledge spillover and the demonstration effect. In their empirical studies of the determinants of TFP, Benhabib and Spiegel (1994) and Engelbrecht (1997) found that the increase in human capital in a country or a region affects the ability of firms to learn and absorb new information, and allows tangible inputs to be used more effectively. Both effects result in efficiency and improvement of productivity. In this context, education may be seen as a threshold effect in that a certain level of investment in human capital may be regarded as a necessary condition for the borrowing of advanced technology, and different levels of schooling are required to implement technologies of different sophistication.

\section{Empirical Results}

In this study we test both $\sigma$ - and $\beta$-convergence using the methods discussed in Sections 2 and 3. $\sigma$-convergence is tested by examining the standard deviation of regional productivity over the period 1985-1999. $\beta$-convergence is tested by estimating Equations (2), (3) and (9), respectively. The data used in testing the convergence hypothesis are explained below.

\subsection{The Data}

The data for all variables used in this study are collected from China's official statistical sources, and the sample covers the period 1985-1999. Any missing value in the series is either interpolated or extrapolated.

The productivity variable used in this study is the industrial value added per employee, and is calculated by dividing the industrial value added in constant prices $\left(Y_{i t}\right)$ by the number of staff and workers in the industry sector $\left(L_{i t}\right)$. The industrial value added variable in current prices, $Y^{\prime}{ }_{i t}\left(=\sum Q_{j i t} P_{j i t}\right.$, where $Q_{j i t}$ and $P_{j i t}$ are the output and price of product $j$ in region $i$ at time $t)$. The index of industrial value added variable, $g_{i t}\left(=\sum Q_{j i t} P_{j i t-1} / \sum Q_{j i t-1} P_{j i t-1}\right)$, is obtained from the China Statistical Yearbook (CSY) (various issues), the Provincial Statistical Yearbook of China (PSYC) (various issues) and the Compilation of New China's Statistics over Fifty Years 1949-1998 (CNCSFY), all of which are published by the National Statistics Bureau of China. These two series allow us to calculate the industrial value added in constant prices, which is $Y_{i t}=Y_{i t-1} \times g_{i t}$. However, in order to calculate $Y_{i t}$, we use the industrial value added in 1985 as benchmark, that is $Y_{i 85}=Y_{i 85}^{\prime}, Y_{i 86}=Y_{i 85} \times g_{i 86}$, and $Y_{i 87}=Y_{i 86} \times g_{i 87}$, and so on. The descriptive statistics of regional productivity are presented in Table 1.

\section{Insert Table 1 here}

The productivity statistics in Table 1 are presented for each province and autonomous region as well as for the three broader geographic regions. These three broad regions are grouped as follows: the east consists of Beijing, Tianjin, Hebei, Liaoning, Shanghai, Jiangsu, Zhejiang, Fujian, Shandong, Guangdong, Hainan and Guangxi; the west refers to Sichuan, Guizhou, Yunnan, Tibet, Shaanxi, Gansu, Qinghai, Ningxia and Xinjiang. The rest is the central region 
that covers Shanxi, Inner-Mongolia, Heilongjiang, Jilin, Anhui, Jiangxi, Henan, Hubei and Hunan.

The statistics show that the regions that exhibit high labour productivities at the beginning of the sample period (1985) are mostly located in China's eastern region. For example, Shanghai's productivity was 9,530 yuan per employee, which is the highest in 1985, followed by Beijing (7,890 yuan), Shandong (7,020 yuan), Tianjin (6,980 yuan) and Guangdong $(6,220$ yuan), giving an average productivity in the eastern region of 6,100 yuan per employee. The productivity of the provinces in the west of China, on the other hand, appears to be the lowest with an average of 3,500 yuan per employee. The figure for the central region is 4,600. However, the poorer provinces in the western and central regions such as Inner Mongolia, Anhui, Jiangxi, Hubei, Hunan, Yunnan, Sichuan, Qinghai, Guizhou and Xinjiang are catching up with their richer counterparts as judged by average productivity growth rates within these two regions over the period 1985-1999. The productivity growth rates of Shanghai, Beijing, Tianjin and Shandong are all below the national average. These productivity statistics apparently suggest that there is a catching-up process at work in China. This initial conclusion will be subjected to the statistical tests described in this and the previous sections.

The labour stock variable, $L_{i t}$, is measured by the staff and workers currently working in the industrial sector. The labour statistics are collected from the CNCSFY.

The capital stock variable, $K_{i t}$, does not exist in any official publications and has to be calculated using the existing investment and fixed asset data. The gross industrial investment $\left(I_{i t}\right)$ is used to calculate $K_{i t}$, and the calculation is based largely but not entirely on Wu (2000b). Estimated capital stock allowing for depreciation for region $i$ at time $t$ is

$$
K_{i t}^{*}=\sum_{h=2}^{t} I_{i h}+K_{i 1}^{*} \quad t=2,3, \ldots, T
$$

$K_{1 t}^{*}$ is the initial value of the capital stock and is obtained from:

$$
K_{i 1}^{*}=\int_{-\infty}^{1} I_{i t} d t=\frac{I_{i 0} e^{r}}{r}
$$

where $r$ is the growth rate of investment and $I_{i t}=I_{i 0} e^{r t} ; r$ and $I_{i 0}$ are obtained from the linear regression using the investment series $I_{i t}$ (where $t=1, \ldots, 15$ ).

The net capital stock with allowance of depreciation for region $i$ at time $t, K_{i t}$, is achieved by multiplying $K_{i t}^{*}$ by the ratio of net industrial asset value (NIAV) to original industrial asset value (OIAV). ${ }^{(1)}$ The gross investment data are collected from the CSY (various issues) and the NIAV and OIAV from the CNCSFY.

Human capital is an important influencing factor in productivity growth as suggested by Lucas (1988 and 1993) and Romer (1990). An increase in human capital in a region affects firms' ability to learn and absorb new technology and information and to make more effective use of tangible inputs. This in turn leads to increases in efficiency and productivity. The human capital variable in this study is measured by average schooling years of employees, and is calculated as a weighted average of total education years received by employees at various levels, with the proportion of employees at each schooling level as the weight, that is: 


$$
H_{i t}=\sum_{k=1}^{4} S Y_{k i t} w_{i k} / \sum_{k=1}^{4} w_{i k}
$$

where $i$ again is the regional subscript, and $k(=1,2,3,4)$ represents the education levels of primary school $(\mathrm{SY}=6)$, junior secondary school $(\mathrm{SY}=9)$, senior secondary school $(\mathrm{SY}=12)$ and college and university $(\mathrm{SY}=16)$.

The data on the composition of employees by education levels for all regions are obtained from the $4^{\text {th }}$ National Population Census in 1990 and the Population Surveys in 1996-1999. The $3^{\text {rd }}$ Population Survey in 1982 and the One-Percent Population Survey in 1987 only contain figures on the education levels for overall population but not on the education levels specifically for employees. We calculate the ratios of regional employees at four education levels to the regional populations at the corresponding education levels in 1990, and then use these ratios to adjust the regional population education level in 1982 and 1987 in order to obtain the average schooling years of employees in 1982 and 1987. The data for 1985, 1986, 1988, 1989 and 1991-1995 are interpolated.

Growth regressions have often used the secondary school enrolment rate or education attainment of the working population as the measure of human capital stock (Barro and Lee, 1996). The problem with this measure is that changes in school enrolment rates only influence the productivity growth with a long lag period. The use of relatively short time series or panel data in productivity modelling prevents the introduction of long lags. The average schooling years of employees do not suffer from this problem and directly measures contributions of human capital to productivity growth.

The sample data cover the period 1985-1999. This sample period is chosen for the following reasons. First, the consistent data on industrial value added across all regions have only been available after 1985. Secondly, the industrial value added covers not only the state-owned and collective-owned firms, but also the township and village enterprises (TVEs) during this period, while the measure before 1985 does not include this last component. Since TVEs have become increasingly important in the development of regional economies, the inclusion of TVE outputs in the productivity measure is desirable. Thirdly, most previous studies on regional disparity use the data up to 1992 (Wu, 2000a). Therefore the empirical results of this study will shed some new light on the most recent trend in regional productivity growth in China.

\subsection{Estimates of Convergence Models}

$\sigma$-convergence is examined by calculating the standard deviations of the log-productivity across regions over the sample period, which are then plotted in Figure 1.

\section{Insert Figure 1 here}

The plots of standard deviations of productivity for all provinces and the three broad regions show that there was a tendency for productivity to converge over the period 1985-1990, while productivity diverged over 1991-1999. Therefore, there is no clear evidence for either convergence or divergence over the whole sample period.

Equations (2) and (3) are estimated based on four panel data sets (the whole nation and eastern, central and western regions). Bearing the plots of standard deviations of productivity in mind, not only is the convergence over the whole period concerned (1985-1999) tested, but the convergence over the sub-periods of 1985-1990 and 1991-1999 is also considered. Since 
the results of Equations (2) and (3) are similar, we only report the estimates of Equation (3) (see Table 2).

Insert Table 2 here

The results show that, when the sub-periods are considered, strong evidence of convergence has been found in all regional cases over the period 1985-1990. Similarly, Wu (2000a) also shows evidence of weak income convergence during 1986-1990 in his $\beta$-convergence tests. During the period 1991-1999, although the values of $\beta$ s are all above 1 , the tendency of divergence is not significant in the eastern and western regions. The results of $\beta$-convergence tests during the two sub-periods confirm those of $\sigma$-convergence tests. When the full data sets are used, the estimated unconditional $\beta$ coefficients are all greater than 1 and statistically significant regardless of the regions under consideration. This suggests that regional productivities in China do not converge during this time period (1985-1999).

However, as we have already discussed in Section (3), unconditional convergence regressions, such as Equations (2) and (3), suffer from many criticisms (de la Fuente, 1997). The main problem with unconditional convergence regressions is that they normally do not fit the data well and leave a large proportion of the variations in productivity growth unexplained. This can be seen by the very low $R$-square values of various regressions in Table 2 , especially the regressions estimated in the second sub-period (1991-1999). Similar results have also been seen in Bernard and Jones (1996).

Hence Equation (9) is estimated to see whether the introduction of explanatory variables would change the conclusions drawn from the unconditional convergence regressions. The estimates of Equation (9) are presented in Table 3.

\section{Insert Table 3 here}

Although the estimated $\beta$ coefficient is insignificant in the model for the central region, it is less than 0 in each of the four models. This suggests that regional productivity does converge over time, although only weak convergence is detected in the central region. The rate of convergence is around $1.3 \%$ per annum. Comparing the $R$-square values in Table 3 with the counterparts in Table 2, we can see that there is a 36.8 percent improvement in the $R$-square values (in the central region's model), and the average improvement is $27.6 \%$, as evaluated by the relative improvement measure (see Edgerton et al, 1996, pp. 91). Compared with those in the time-series models, the $R$-square values in Table 3 are still relatively low. However, this is common in convergence analysis with panel data (see, for example, Baumol et al, 1989; Grier and Tullock, 1989; Mankiw et al, 1992; de la Fuente, 1997; Rassekh et al, 2001).

Considering the contribution of each input factor in the catch-up process, we find that the human capital variable is positive and significantly different from 0 in each of the four models. This suggests that the labour quality, measured by average schooling years, has played an important role in the productivity catch-up process. According to the figures in 1999, the calculated average schooling years of employees in western, central and eastern regions are 6.7, 7.7 and 8.0, respectively. The gap between the west and east is particularly significant. As the catch-up cost is negatively related to the size of the gap in an open economy, the western regions enjoy a greater opportunity to improve its human capital stocks.

Moreover, the scale elasticity of human capital (0.387) is larger than that of physical capital (0.344) and labour (0.269) in the national model suggesting that the improvement of labour 
quality is crucial for the elimination of productivity gaps between Chinese regions. This is more evident in the model for the eastern and central regions, as the scale elasticities of human capital are as high as 0.459 and 0.645 , respectively. This is because the provinces in these regions have been relatively well developed and the catch-up process within these subregions depends largely on the improvement of human capital.

The inability of the unconditional convergence regressions to identify the catch-up process among Chinese regions has been echoed in the studies on per capita income and productivity convergence for other countries. For example, De Long (1988) finds that unconditional convergence regressions can only detect convergence when rich industrialised countries are concerned, but this conclusion is reversed when additional countries, especially some less developed countries, are included in the sample. However Baumol et al (1989), Barro (1991) and many other researchers find that when additional factors, such as physical and human capital variables, are introduced into the convergence models, income convergence becomes evident. This suggests that when testing for productivity/income convergence, conditional convergence models are more appropriate than unconditional ones.

\section{Concluding Remarks}

This paper has examined the regional productivity convergence in the Chinese industry using the latest dataset available. Although the tests for $\sigma$-convergence and the unconditional $\beta$ convergence regressions only detect the regional productivity convergence during the period 1985-1990, the conditional $\beta$-convergence model, developed based on the Cob-Douglas production function that incorporates a human capital variable, suggests that the convergence occurs over the whole period (1985-1999), and that the convergence rate is around $1.3 \%$ per annum. The results of the productivity convergence in the industrial sector may contribute to a better understanding of China's economic growth across regions, especially during the reform period.

Human capital is found to be an important factor contributing to the elimination of productivity differentials between Chinese regions. The implication of this result is that the policymakers in both central and local governments should pay much attention to the improvement of labour quality, as knowledge spillovers and technological innovations within regions are vital to productivity growth. China's accession to the WTO is expected to accelerate this regional catching-up process if investments by multinational firms in both physical capital and human capital could be successfully channelled to the inland regions given their cost advantages. However, the government has to play an active role in promoting these regions and to give incentives to international firms to invest in these regions.

Other potentially influencing factors, such as international trade and investment, may also be considered in the production function in order to improve the goodness-of-fit further. The establishment of a smooth channel for FDI to flow into the inland, particularly the western regions, would also be of interest.

\section{Note}

(1) OIAV is a variable that summates firms' investment in fixed assets over time, and NIAV is obtained by deducting the depreciation of fixed assets from OIAV. OIAV and NIAV are calculated by summating firms' investment expenditure on fixed assets in current prices, and they cannot be used as measures of the capital stock. However, the ratio of NIAV to OIAV can serve as a measure of depreciation rate for fixed capital stocks. 


\section{References}

Bairam, E. I. and McRae, S. D., "Testing the Convergence Hypothesis: A New Approach," Economics Letters, 1999, 64, pp. 351-355.

Barro, R., "Economic Growth in a Cross-section of Countries," Quarterly Journal of Economics, 1991, CVI, pp. 407-443.

Barro, R. J. and Lee, J. W., "International Measures of Schooling Years and Schooling Quality," American Economic Review, Papers and Proceedings, 1996, 68, pp. $29-52$.

Barro, R. J. and Sala-I-Martin, X., "Convergence," Journal of Political Economy, 1992, 100, pp. 223-251.

Barro, R. J. and Sala-I-Martin, X., Economic Growth. New York: McGraw-Hill, 1995.

Baumol, W., "Productivity Growth, Convergence and Welfare: What the Long-Run Data Show," American Economic Review, 1986, 78, pp. 1072-1085.

Baumol, W., Blackman, S. A. B. and Wolff, E. N., Productivity and American Leadership: The Long View. Cambridge, MA: MIT Press, 1989.

Bernard, A. B., and Jones, C. I., "Comparing Apples to Oranges: Productivity Convergence and Measurement across Industries and Countries," American Economic Review, 1996, 86, pp. 1216-1238.

Benhabib, J. and Spiegel, M., "The Role of Human Capital in Economic Development: Evidence from Aggregate Cross-Country Data,” Journal of Monetary Economics, 1994, 34, pp. 143-173.

Bliss, C., "Galton's Fallacy and Economic Convergence," Oxford Economic Papers, 1999, 51, pp. 414.

Breitung, J. and Meyer, W., "Testing for Unit Root in Panel Data: Are Wages on Different Bargaining Levels Cointegrated?" Applied Economics, 1994, 26, pp. 353-361.

Caree, M. A., Klomp, L. and Thurik, A. R., "Productivity Convergence in OECD Manufacturing Industries,” Economics Letters, 2000, 66, pp. 337-345.

Chen, B. and Feng, Y., "Determinants of Economic Growth in China: Private Enterprise, Education and Openness," China Economic Review, 2000, 11, pp. 1-15.

Choi, H. and Li, H., "Economic Development and Growth Convergence in China," Journal of International Trade and Economic Development, 2000, 9, pp. 37-54.

de la Fuente, A., "The Empirics of Growth and Convergence: A Selective Review," Journal of Economic Dynamics and Control, 1997, 21, pp. 23-73.

De Long, B., "Productivity Growth, Convergence and Welfare: Comment," American Economic Review, 1988, 78, pp. 1138-1154.

Edgerton, D. L., Assarsson, B., Hummelmose, A., Laurila, I. P., Rickertsen, K. and Vale, P. H., The Econometrics of Demand Systems with Applications to Food Demand in the Nordic Countries, London: Kluwer Academic Publishers, 1996.

Engelbrecht, H. J., "International R\&D Spillovers, Human Capital and Productivity in OECD Economies: An Empirical Investigation," European Economic Review, 1997, 41, pp. 14791488.

Fujita, M and Hu, D., "Regional Disparity in China 1985-1994: the Effects of Globalization and Economic Liberalization,” Annals of Regional Science, 2001, 35, pp. 3-38.

Gerschhenkron, A., "Economic Backwardness in Historical Perspective," in

B. F. Hoseliz eds., The progress of Underdeveloped Areas. Chicago: University of Chicago Press, 1952, pp. 3-29. 
Gustafsson, B. and Shi, L., "The Anatomy of Rising Earnings Inequality in Urban China," Journal of Comparative Economics, 2001, 29, pp. 118-135.

Goddad, J. and Wilson, J., "Cross Section and Panel Estimation of Convergence," Economics Letters, 2001, 70, pp. 327-333.

Grier, K. and Tullock, G., "An Empirical Analysis of Cross-National Economic Growth, 1951-80," Journal of Monetary Economics, 1989, 24, pp. 259-276.

Gundlach, E., "Regional Convergence of Output per Worker in China: A Neo-classical Interpretation," Asian Economic Journal, 1997, 11, pp. 423-442.

Jian, T., Sachs, J. D. and Warner, A.M., "Trends in Regional Inequality in China,” China Economic Review, 1996, 7, pp. 1-21.

Kuznets, S., Population, capital and Growth: Selected Essays. New York: W. W. Norton and Company, 1973.

Lee, J., "Changes in the source of China's regional inequality," China Economic Review, 2000, 11, pp. 232- 245 .

Lucas, R., "On the Mechanics of Economic Development," Journal of Monetary Economics, 1988, 22, pp. 3-42.

Lucas, R., "Making a Miracle,” Econometrica, 1993, 61, pp. 251-272.

Mankiw, G., Romer, R. and Weil, D., "A Contribution to the Empirics of Economic Growth," Quarterly Journal of Economics, 1992, CVII, pp. 407-437.

McCuun, A. and Huffman, W. E., "Convergence in U.S. Productivity Growth for Agriculture: Implications of Interstate Research Spillovers for Funding Agricultural Research,” American Journal of Agricultural Economics, 2000, 82, pp. 370-388.

Raiser, M., "Subsidising Inequality: Economic Reforms, Fiscal Transfers and Convergence across Chinese Provinces," Journal of Development Studies, 1998, 34, pp. 1-26.

Rassekh, F., Panik, M. J. and Kolluri, B. R., "A Test of the Convergence Hypothesis: The OECD Experience, 1950-1990," International Review of Economics and Finance, 2001, 10, pp. 147157.

Ravallion, M. and Jalan, J., "Growth Divergence due to Spatial Externalities," Economics Letters, 1996, 53, pp. 227-232.

Romer, P., "Endogenous Technological Change," Journal of Political Economy, 1990, 98, S71S102.

Solow, R., "A Contribution to the Theory of Economic Growth," Quarterly Journal of Economics, 1956, LXX, pp. 65-94.

Song, S., Chu, G. S-F. and Cao, R., "Intercity Regional Disparity in China," China Economic Review, 2000, 11, pp. 246-261.

Wolff, E. N., "Human Capital Investment and Economic Growth: Exploring the Cross-country Evidence," Structural Change and Economic Dynamics, 2000, 11, pp. 433-472.

Wu, Y., "Income Disparity and Convergence in China's Regional Economies," in

P. J. Lloyd and X. G. Zhang eds., China in the Global Economy. Cheltenham, UK: Edward Elgar Publising Ltd, 2000 (a), pp. 261-281.

Wu, Y., "Is China's Economic Growth Sustainable? A Productivity Analysis," China Economic Review, 2000 (b), 11, pp. 278-296.

$\mathrm{Xu}$, L. C. and Zou, H., "Explaining the Changes of Income Distribution in China," China Economic Review, 2000, 11, pp. 149-170. 
Yao, S., "Economic Growth, Income Inequality and Poverty in China under Economic Reforms," Journal of Development Studies, 1999, 35, pp. 104-130. 
Table 1

Descriptive Statistics of Productivity

\begin{tabular}{|c|c|c|c|c|c|}
\hline Region & $\begin{array}{l}\text { Initial } \\
\text { Level } \\
\text { (1985) }\end{array}$ & $\begin{array}{c}\text { Initial } \\
\text { Growth Rate } \\
(1986)\end{array}$ & $\begin{array}{c}\text { Final Level } \\
\text { (1999) }\end{array}$ & $\begin{array}{c}\text { Final } \\
\text { Growth Rate } \\
(1999)\end{array}$ & $\begin{array}{c}\text { Average } \\
\text { Growth Rate } \\
(1985-1999)\end{array}$ \\
\hline Beijing & 7.89 & 3.57 & 23.17 & 9.88 & 8.00 \\
\hline Tianjin & 6.98 & -0.07 & 20.46 & 21.67 & 7.99 \\
\hline Hebei & 5.77 & 0.01 & 27.23 & 13.95 & 11.72 \\
\hline Shanxi & 5.03 & -0.96 & 15.22 & -0.30 & 8.24 \\
\hline Inner Mongolia & 3.69 & -1.27 & 19.88 & 16.37 & 12.79 \\
\hline Liaoning & 5.54 & -0.39 & 23.02 & 23.60 & 10.71 \\
\hline Jilin & 3.84 & -3.38 & 16.52 & 27.95 & 10.99 \\
\hline Heilongjiang & 5.08 & -6.19 & 22.05 & 26.40 & 11.06 \\
\hline Shanghai & 9.53 & -1.16 & 34.92 & 18.12 & 9.72 \\
\hline Jiangsu & 4.96 & -2.44 & 29.54 & 16.35 & 13.60 \\
\hline Zhejiang & 4.87 & 6.19 & 35.79 & 12.81 & 15.31 \\
\hline Anhui & 4.67 & 6.40 & 29.37 & 14.80 & 14.04 \\
\hline Fujian & 4.85 & -2.13 & 30.00 & 13.67 & 13.91 \\
\hline Jiangxi & 3.72 & 1.67 & 21.62 & 13.43 & 13.39 \\
\hline Shandong & 7.02 & -6.06 & 25.83 & 12.31 & 9.75 \\
\hline Henan & 4.84 & 9.66 & 19.29 & 12.23 & 10.38 \\
\hline Hubei & 4.98 & -6.17 & 25.74 & 22.29 & 12.45 \\
\hline Hunan & 4.48 & 1.41 & 22.22 & 4.39 & 12.11 \\
\hline Guangdong & 6.22 & 1.34 & 28.77 & 8.53 & 11.56 \\
\hline Guangxi & 4.34 & 15.80 & 21.69 & 17.72 & 12.19 \\
\hline Hainan & 4.29 & 9.94 & 21.96 & 21.36 & 12.37 \\
\hline Sichuan & 2.28 & -1.51 & 27.35 & 15.93 & 19.43 \\
\hline Guizhou & 4.79 & -1.10 & 20.41 & 9.73 & 10.92 \\
\hline Yunnan & 4.87 & 9.95 & 33.19 & 7.31 & 14.70 \\
\hline Tibet & 6.15 & -21.71 & 11.14 & 9.26 & 4.34 \\
\hline Shaanxi & 4.11 & 3.53 & 16.39 & 8.34 & 10.38 \\
\hline Gansu & 5.53 & -2.35 & 15.09 & 9.15 & 7.43 \\
\hline Qinghai & 3.60 & 14.89 & 17.67 & 13.18 & 12.03 \\
\hline Ningxia & 4.23 & -8.43 & 11.54 & 10.31 & 7.43 \\
\hline Xinjiang & 5.41 & 6.77 & 21.08 & 20.27 & 10.20 \\
\hline East & 6.10 & -0.34 & 28.09 & 14.56 & 11.53 \\
\hline Central & 4.60 & -0.26 & 21.40 & 15.39 & 11.60 \\
\hline West & 3.50 & 0.79 & 22.9 & 11.98 & 14.36 \\
\hline All Regions & 5.17 & -0.17 & 25.37 & 14.72 & 12.02 \\
\hline
\end{tabular}


Table 2 Estimates of Unconditional $\beta$-Convergence Regressions (Equation 3)

\begin{tabular}{c|cccc}
\hline \multirow{2}{*}{ Region } & Estimation period & $\beta-1$ & S.E. & $R^{2}$ \\
\hline \multirow{3}{*}{ Whole nation } & $1985-1999$ & $0.107^{*}$ & 0.012 & 0.208 \\
& $1985-1990$ & $-0.315^{*}$ & 0.056 & 0.348 \\
& $1991-1999$ & $0.055^{*}$ & 0.018 & 0.123 \\
\hline \multirow{3}{*}{ East } & $1985-1999$ & $0.095^{*}$ & 0.016 & 0.226 \\
& $1985-1990$ & $-0.232^{*}$ & 0.082 & 0.290 \\
& $1991-1999$ & 0.029 & 0.024 & 0.096 \\
\hline \multirow{3}{*}{ Central } & $1985-1999$ & $0.149^{*}$ & 0.023 & 0.280 \\
& $1985-1990$ & $-0.456^{*}$ & 0.120 & 0.326 \\
& $1991-1999$ & $0.097^{*}$ & 0.033 & 0.139 \\
\hline \multirow{3}{*}{ West } & $1985-1999$ & $0.083^{*}$ & 0.026 & 0.157 \\
& $1985-1990$ & $-0.310^{*}$ & 0.099 & 0.391 \\
& $1991-1999$ & 0.045 & 0.039 & 0.138 \\
\hline
\end{tabular}

Note: * indicates that the estimate is statistically significant at the $5 \%$ test level (two-tailed). 
Table $3 \quad$ Estimates of Conditional Convergence Models (1985-1999)

\begin{tabular}{c|cccc}
\hline Variable & Whole Nation & East & Central & West \\
\hline \multirow{2}{*}{ Constant } & $0.138^{*}$ & $0.149^{*}$ & $0.132^{*}$ & $0.130^{*}$ \\
& $(0.005)$ & $(0.010)$ & $(0.016)$ & $(0.009)$ \\
$Y_{i 0} / L_{0 i}$ & $-0.013^{*}$ & $-0.011^{*}$ & -0.004 & $-0.013^{*}$ \\
& $(0.001)$ & $(0.006)$ & $(0.013)$ & $(0.002)$ \\
$\Delta(k-l)_{i t}$ & $0.344^{*}$ & $0.247^{*}$ & $0.215^{*}$ & $0.460^{*}$ \\
$\Delta(h-l)_{i t}$ & $(0.044)$ & $(0.077)$ & $(0.107)$ & $(0.130)$ \\
$R^{2}$ & $0.387^{*}$ & $0.459^{*}$ & $0.645^{*}$ & 0.188 \\
$b$ & $(0.056)$ & $(0.095)$ & $(0.127)$ & $0.149)$ \\
& 0.424 & 0.346 & 0.545 & 0.386 \\
& 0.269 & 0.294 & 0.140 & 0.352 \\
\hline
\end{tabular}

Note: see Table 2. 


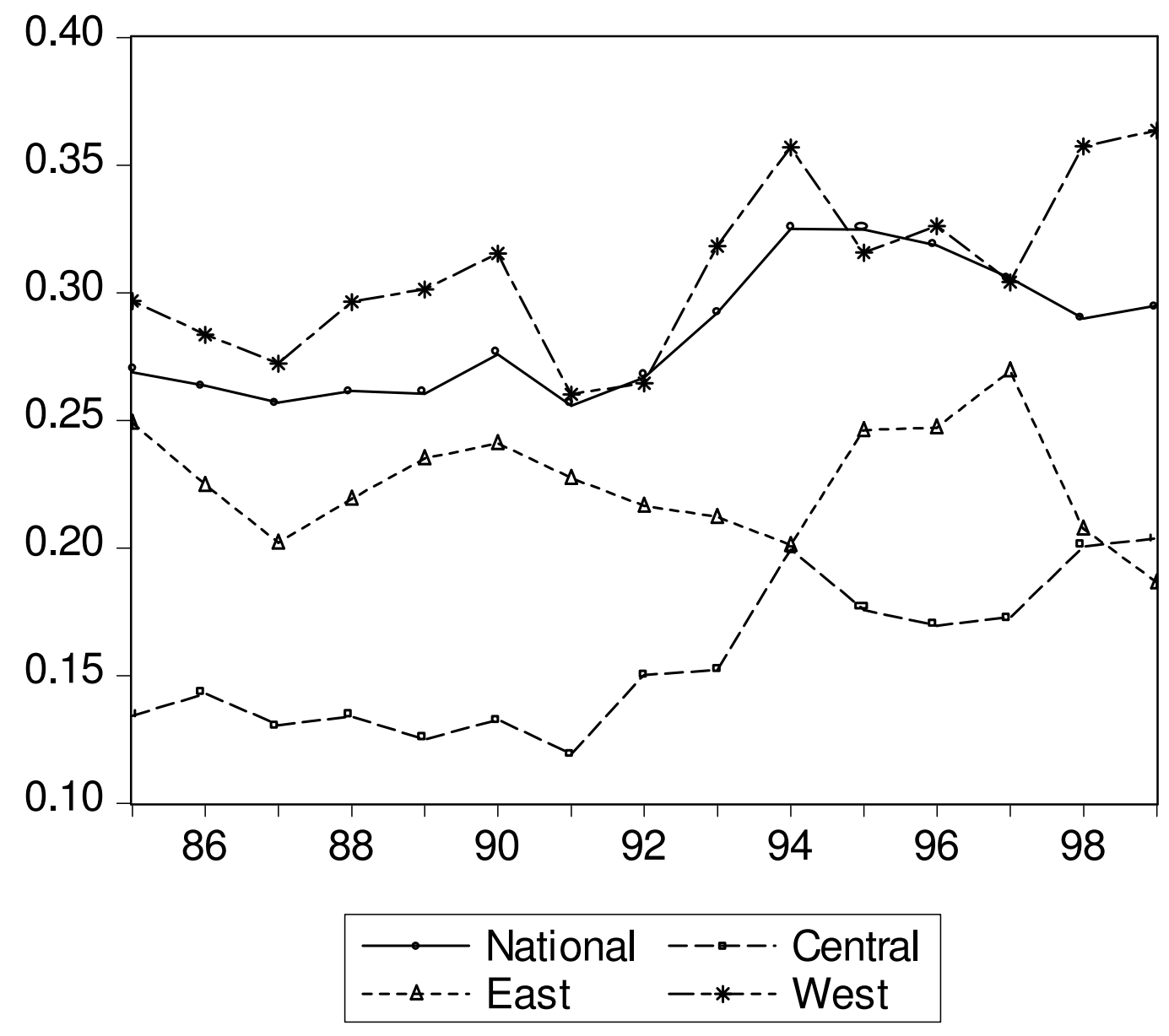

Figure 1: Standard Deviations of Productivity among Chinese Regions (1985-1999) 